\title{
AS RELAÇÕES HOMEM-NATUREZA E O DILEMA ECOLÓGICo
}

\section{Thais Martins Echeverria}

\begin{abstract}
RESUMO: Neste trabalho, procuro examinar diferentes interpretações das relações homem-natureza e dos dilemas ecológicos, através da análise da posição de autores paradigmáticos como Paehlke, Eckersley e Habermas, com auxílio da classificação proposta por Lester. Diante da multiplicidade de visões sobre a questão ecológica, procuro compreendê-las, interpretá-las e construir uma leitura apoiada em Habermas, Drysek e Brüzeke. Trata-se de uma alternativa que trabalha a noção de desenvolvimento sustentado, entendida como uma idéia-força que possibilite a busca de modos tecnológicos pautados por uma racionalidade ecológica que articule, em rede, uma infinidade de projetos particulares de "sociedades sustentáveis".
\end{abstract}

UNITERMOS: Relações homem-natureza, ecologia, racionalidade, ideologia, desenvolvimento sustentado, redes, sociedades sustentáveis.

\section{Os MÚlTIPLOS OlHARES SOBRE A QUESTÃo}

A literatura contemporânea das ciências sociais na área de ecologia e meio ambiente tem evidenciado olhares diferenciados e propostas polissêmicas, no que se refere à compreensão das relações Homem-Natureza e dos Dilemas Ecológicos. Proponho-me a examinar algumas tendências teóricas subjacentes a esses olhares, através da análise da posição de alguns autores paradigmáticos. Selecionei para essa discussão um ecologista moderado 
(Paehlke, 1989), um teórico ecocêntrico ligado ao movimento da ecologia profunda (Eckersley, 1990), e um filósofo contemporâneo (Habermas, 1986, 1987a, 1987b, 1987c, 1994) que inspira discussões de ambientalistas (Drysek, 1987; Brandão, 1994; Brüzeke, 1994) sobre novas concepções de racionalidade aplicáveis ao estudo da realidade ambiental. Para proceder a tal análise, vou inspirar-me nos trabalhos de Lester (1990) e Ferreira (1992).

\section{SISTEMATIZANDO OS OLHARES}

Tal como fazem Lester (1990), em relação às teorias referentes à questão ambiental, e Ferreira (1992), em relação à problemática ambiental do Estado de São Paulo, analiso as visões de mundo e os projetos de futuro relativos a esta matéria, subjacentes às abordagens que os referidos autores fazem das relaçòes homem-comunidade-natureza. Desenvolvo meu trabalho empregando a classificação proposta por Lester (1990) para ordenar a produção teórica sobre meio ambiente na área de ciências sociais. $\mathrm{O}$ autor procede a esta ordenação através do emprego de categorias que permitem classificar, comparar e compreender as diferenças entre os mais diversos conceitos, diagnósticos e propostas de futuro ambiental. Tais categorias são o individualismo, o comunitarismo, a centralização e a descentralização, as quais refletem as principais orientações de valores que dividem e opõem diferentes tradições teóricas no campo das ciências sociais.

A orientação individualista, herdeira do iluminismo e da revolução industrial, abrange tanto as propostas teóricas que fazem apologia dos sistemas de mercado, como de outros modelos econômicos neoliberais. A vertente comunitarista engloba propostas teóricas clássicas conservadoras e variações do socialismo, assumindo ora uma cosmovisão antropocêntrica, ora uma cosmovisão biocêntrica. Já a centralização é a orientação presente na visão dos ecologistas que defendem a existência de um poder central coercitivo e regulador das relações homem-natureza. Em oposição, a 
descentralização é a idéia-força que norteia o pensamento dos ecologistas defensores da mobilização e organização da sociedade civil como uma estratégia de luta contra a crise ambiental. Combinando-se as duas dimensões que marcam os diferentes "locus das soluções" com as dimensões que marcam os diferentes "locus de valores", temos, de acordo com Lester (1990, p.317), a seguinte tipologia de visões de mundo ambientalista: hobsonianos e reformistas estruturalistas, guardiões, ecologistas reformistas, conservadores centrados no livre mercado, ecologistas sociais e ecologistas profundos. ${ }^{1}$

Os hobsonianos e os reformistas estruturalistas, teóricos que se situam dentro de uma orientação individualista liberal, preconizam, através de diferentes estratégias, a presença de um Estado central controlador com o intuito de disciplinar as relações homem-natureza e as questões ambientais decorrentes. O papel do Estado, na visão dos hobsonianos, seria o de regular os apetites individuais entre os diferentes atores sociais, uma vez que tais relações não disciplinadas poderiam resultar em uma guerra de todos contra todos, o que conduziria à entropia e resultaria em caos ambiental. Exemplos dessa orientação estão contidos na teoria do 'Estado estável", de Daly (apud Ferreira, 1992), ou nas teorias que buscam inspiração na dinâmica da escassez, a partir das premissas do dilema da "tragedy of the commons" (Hardin, 1968).

Os reformistas estruturais, mais moderados que o grupo anterior, preconizam ora a implementação de politicas publicas mais centralizadas (Lester, 1990), ora formas institucionalizadas c corporativas de coordenação ambiental, que envolvam diálogo entre o Estado, grupos de interesse e ambientalistas (Leonard, Davies, Binder; apud Lester, 1990).

'Detalhes desta tipologia podem ser encontrados em Lester, J. et al. Alternative views of Environmental Problematic. In Environmental Politics and Poligy. Lester, J.( org.), Duke University Press, 1990. E, dentro de uma perspectiva mais ampla, e com outra organização, em Ferreira, L. C. Estado e Ecologia: Novos Dilemas e Desafios. Campinas: UNICAMP, 1992. Tese (Doutorado em Ciências Sociais) - Instituto de Filosofia e Ciências Humanas, Universidade Estadual de Campinas, 1992.

Temáticas, Campinas, 4(7):9-29, jan./jun. 1996 
O termo guardiões, segundo Lester (1990, p.319), aplica-se a grupos defensores do monopólio do poder político pelos especialistas, cientistas, ou outras categorias que detenham uma capacidade intelectual ou ideológica relevante para o gerenciamento das relações homem-natureza e dos dilemas ambientais. Este grupo é constituído por uma mistura de marxistas, tecnocratas e conservadores. Classificam-se nesta categoria alguns aspectos do trabalho de Ophuls (apud Lester, 1990), que preconiza uma política ambiental comunitária, coordenada centralmente pelos ecologistas, e de autores que defendem uma tecnocracia ambiental, como Weinberg (apud Lester, 1990).

Os ecologistas reformistas sào pensadores que consideram as questões ambientais como a problemática central dentro do sistema político. Priorizam valores biocêntricos, holísticos e uma estratégia sistêmica, comunitária e integrada na abordagem dos problemas ambientais. Buscam implementar tal orientação através de políticas públicas direcionadas para o equilibrio, integridade e estabilidade dos ecossistemas, para a estabilização da população, manejo integrado do solo e controle das fontes de poluição. Os diversos pesos que tais aspectos ganham nas propostas das várias facções deste grupo conferem-lhe diferentes coloridos. Entre os ecologistas reformistas destacam-se Paul Erlich (apud Lester, 1990) e Eugene Odum (1971).

Os defensores do livre mercado constituem a categoria na qual Lester (1990, p.321) classifica os pensadores que defendem a racionalidade dos sistemas de mercado auto-regulados. Estes autores acreditam que o livre jogo de mercado assegura a possibilidade de atendimento das necessidades individuais, inclusive aquelas relativas aos bens ambientais, tais como ar puro, água potável, etc. Por outro lado, tais autores negam a eficácia da intervenção governamental nas questões de meio ambiente e opõem-se aos mecanismos centralizados de regulação da política ambiental, adotando uma postura eminentemente individualista. Destacam-se neste grupo autores como Julian Simon e Murray Weidenbaun (apud Lester, 1990).

Ecologistas sociais é a denominação que Lester emprega para identificar os pensadores ambientalistas que preconizam uma política sócioTemáticas, Campinas, 4(7):9-29, jan./jun. 1996 
ecônomica descentralizada e participativa. Trata-se de um grupo que assume uma visão da esquerda libertária, nega a centralização e faz, com freqüência, apologia da cooperação comunitária por oposição à competição. Estão incluídos neste grupo os eco-anarquistas, as eco-feministas, e os teóricos críticos, como Drysek (1987) e Brüzcke (1994).

Os eco-anarquistas propõem, com muitas variantes, o resgate da harmonização com a natureza a partir da harmonização das relações dos homens entre si. Pregam uma sociedade não hierarquizada, descentralizada e comunitária. Dentre as eco-feministas predomina uma postura de negação dos valores e da hierarquia patriarcal, bem como propostas de descentralizaçào da politica ambiental e de maior harmonização nas relações com a natureza.

Os teóricos críticos, inspirados em Habermas, partem de uma crítica da modernidade $\mathrm{c}$ do tipo de racionalidade técnico-instrumental em que ela se baseia. Buscam desenvolver conceitos alternativos de racionalidade, tais como o de racionalidade ecológica, empregado por Drysek (1987) e o de racionalidade ampla, empregado por Brüzeke (1994). A abordagem desenvolvida pelos teóricos críticos tem um viés antropocêntrico e comunitarista.

Os ecologistas profundos constituem-se em grupos que elegem o sistema biótico como locus de valores (Lester, 1990, p.317) e pregam o equilibrio, a integridade e auto-realização desse sistema. Defendem uma política ambiental descentralizada, holística, não hierarquizada e voltada para aspirações de resgate do sagrado nas relações entre os seres vivos. Dentre os ecologistas profundos destacam-se Arne Naess (apud Eckersley, 1990), Capra (1983) e Eckersley (1990).

\section{UMA ANÁLISE DOS DIFERENTES OLHARES}

A taxionomia desenvolvida por Lester auxilia-nos a compreender a estrutura básica do pensamento de diferentes ambientalistas, a refletir sobre scus diagnósticos, concepções e projetos de futuro ambiental, bem como a Temáticas, Campinas, 4(7):9-29, jan./jun. 1996 
situá-los, criticamente, em termos da realidade contemporânea. Assim, vou analisar a partir dela as posiçòes de Paehlke (1989), Habermas (1968, 1987a, 1987b, 1987c, 1987d, 1994) e Eckersley (1990).

\section{A Visão moderada de PaEHLKe}

Paehlke, em Evironmentalism and The Future of Progress Politics (1989), discute as bases de uma ideologia ambientalista, mostrando que dentro de uma visão ecológica não pode haver dicotomia entre homem e natureza. Isto porque cada organismo integra uma cadeia complexa e cíclica de interdependências, cuja sobrevivência depende da existência de todos os componentes. Como defensor da ecologia, o autor defende a limitação do uso da natureza, uma vez que as relações custo-beneficio do mesmo são frequentemente negativas. Por outro lado, considerando a limitação das sociedades humanas pelos referentes físicos e biológicos de seu ambiente, Pachlke propõe estratégias de desenvolvimento que convivam com essas restriçòes e não dependam do uso progressivo de materiais e energia. Nessa perspectiva, o mundo natural $\mathrm{e}$ seus produtos não são visualizados como um conjunto de recursos a serem usados pelo homem e suas comunidades, mas como elementos de uma mesma cadeia da vida.

Segundo Paehlke (1989, p.277), a ação dos ambientalistas é marcada por diretrizes tais como: 1) promover a proteção ambiental, tanto no que se refere aos aspectos preservacionistas, como aos relativos ao controle da poluição; 2) opor-se a um rápido crescimento econômico e não considerar como sagradas as regras de mercado; 3) promover as transformações tecnológicas associadas com a automação, a comunicação e, ao mesmo tempo, condenar as indústrias poluidoras; 4) promover a redução dos gastos governamentais; 5) inclinar-se para uma política de descentralização; 6) encorajar a redução do tempo de trabalho, em vez do pleno emprego; 7) promover empreendimentos de pequena e média escala; 8) atribuir importância central 
ao desenvolvimento de inovações e a participação nas instituições políticas e administrativas. No que se refere a este último aspecto, o autor considera que uma orientação ambientalista na direção do desenvolvimento sustentável requer considerável mobilização social para obter-se reajustes nos hábitos do dia a dia. Tais transformações, segundo o autor, não se fazem sem participação pública.

Paehlke (1989) é integrante do "movimento histórico", conforme classificação utilizada por Viola, uma vez que parte da

“... conceptualização de que a civilização contemporânea é insustentável no médio e longo prazo devido a quatro fatores principais: crescimento populacional exponencial, depleção da base de recursos naturais, sistemas produtivos que utilizam tecnologias poluentes e de baixa eficiência energética, e sistema de valores que propiciam a expansão ilimitada do consumo material..." (Viola, 1992$, p. 8$)^{2}$

Além disso, desenvolve uma abordagem histórica, filosófica e política do ambientalismo, assumindo uma perspectiva considerada globalista, direcionada para um compromisso de reforma da ordem mundial na direção da sustentabilidade ambiental, com um certo colorido biocêntrico. No que se refere ao "locus de solução" (Lester, 1990, p.317) para a política ambiental, Pachlke pode ser pensado como partidário moderado de um processo de descentralização multissetorial.

Confrontando as propostas de Paehlke (1989) com o esquema de Lester (1990), ele situa-se como um ecologista reformista, com ênfase em um discurso biocêntrico, holístico, centrado na adoção gradual e participativa de uma proposta de desenvolvimento sustentado. $O$ autor parece pretender alcançar, através de um processo de desenvolvimento sustentado, apoiado na participação de um movimento ambientalista capilarizado e multissetorial, a superação da oposição centralização e descentralização.

${ }^{2}$ De acordo com Viola (1992) os movimentos ecológicos podem ser classificados em três grupos: novo movimento social, grupo de interesse e movimento histórico.

Temáticas, Campinas, 4(7):9-29, jan./jun. 1996 
Embora tal orientação o afaste dos modelos centralizadores dos ecologistas reformistas, sua posição moderada, no que se refere a um modelo de sociedade participativa, não sugere sua classificação entre os ecologistas sociais, ao lado dos teóricos críticos ou dos ecologistas radicais.

\section{As Relações Homem-Natureza de ACordo com a Teoria CrítítCA}

Habermas, em seu trabalho Ciencia Y Técnica Como "Ideologia" (1968), dialoga com os teóricos críticos da Escola de Frankfurt, Max Horkheimer, Theodor Adorno e, mais notadamente, Herbert Marcuse, que introduziram uma inovação temática significativa na discussão das relações homemnatureza, através de suas críticas à dominação da natureza. Ao contrário da visão marxiana acerca da marcha progressiva da história, que enfatizava o potencial liberatório do domínio crescente da natureza através do desenvolvimento das forças produtivas, os autores em questão viam esse desenvolvimento como essencialmente negativo. Isto porque dele decorre uma dominação da natureza, em sentido amplo, envolvendo tanto a sujeição da natureza interna do homem, como da natureza externa a ele, constituida pelo ambiente. Tal dominação, que se reflete negativamente tanto na crise ambiental como na felicidade da humanidade, é exercida através de uma divisão do trabalho repressiva, tanto do ponto de vista psíquico, como social.

Os filósofos críticos mencionados, especialmente Marcuse (apud Habermas, 1968), argumentavam que a racionalidade instrumental não deveria tornar-se o paradigma da sociedade moderna e que as relações entre natureza e sociedade não deveriam permanecer sujeitadas a leis manipuladas por uma elite tecnocrata.

Habermas (1968, 1987a, 1987b, 1994) fez uma revisão dessa crítica da racionalidade instrumental, mostrando que a extensão da racionalidade pragmática às esferas sociais e políticas burocratiza e reifica o mundo da 
vida. Localizou a razão instrumental como parte de uma teoria mais ampla da racionalidade e submeteu-a ao crivo da razão crítica. Em Teoria de La Acion Comunicativa II (1987c), dialogando com Neunendorff (apud Habermas, 1987 c, p.507), afirma que a vida social reproduz-se através de ações racionais com relaçào a fins, controladas por meios generalizados de comunicação e por uma vontade comum ancorada na prática comunicativa de todos os indivíduos.

Habermas (1968) assumiu uma posição contrária à de Marcuse, no que se refere à questão da ciência e da tecnologia, pois este acreditava na possibilidade de desenvolvimento de uma nova ciência, que colocasse a natureza mais como sujeito do que como objeto de controle técnico. Isto porque Habermas considerava a ciência e a tecnologia como formas de conhecimento guiadas pelo interesse do homem na sua sobrevivência, e como uma maneira de conhecer limitada pelo modo ìnstrumental, através da qual os homens percebem e relacionam-se com a natureza. Segundo esta perspectiva, a ciência e a tecnologia sào determinadas pelo caráter objetivo desta relação consubstanciada no trabalho, e que se traduz- na luta do homem com a natureza, para assegurar suas condições de subsistência.

Em Conbecimento e Interesse (1987a), o autor desenvolve um novo conceito de teoria crítica, baseado na constituição do conhecimento, através dos três diferentes tipos de interesses que guiam sua produção: o técnico, o prático e o cmancipatório. O interesse técnico guia a investigação desenvolvida pelas ciências naturais em busca de generalizações e do estabelecimento de leis que possibilitem a previsão e o controle dos eventos. $\mathrm{O}$ interesse cognitivo prático orienta o conhecimento desenvolvido pelas ciências histórico-hermenêuticas, no sentido do entendimento interpretativo dos processos de interação social. Tal conhecimento tem por finalidade assegurar as oportunidades de auto-entendimento e do entendimento mútuo entre os indivíduos no decorrer da vida social. O interesse emancipatório guia a reflexão crítica sobre as relações de poder, e procura assegurar a emancipação dos indivíduos, através da consciência das restrições que pesam sobre eles, 
tais como as constituídas pelo trabalho alienado e pela comunicação distorcida.

A atualidade desta reflexão, uma vez que Habermas não acredita mais na teoria do conhecimento como via regia, conforme expõe em entrevista denominada Um Perfil Filosófico Político (1987d), está em seu aporte político. Partindo da separação entre trabalho e comunicação, e fundamentando o conhecimento relativo a cada uma destas esferas em diferentes interesses cognitivos, o autor foi capaz de rejeitar a tese pessimista da escola de Frankfurt de que o progresso técnico traz regressão moral e sujeição sóciopsicológica dos indivíduos.

Para Habermas (1968), os problemas das sociedades desenvolvidas e industriais não derivam do fato de que as relações entre o homem e natureza através do trabalho sejam pautadas por uma racionalidade instrumental. Tais problemas decorrem do fato de que esta racionalidade não tem sido acompanhada, ou mesmo hierarquizada, pela racionalização das normas sociais na esfera comunicativa. Essa autonomização entre as esferas mencionadas tem favorecido o desenvolvimento de processos de reificação da ciência e de outras formas de colonização do mundo da vida. Em função dessa questão, nas sociedades de capitalismo avançado ocorre uma relativização da separação entre interação e trabalho, uma vez que, através da reificação do conhecimento científico, a técnica se autonomiza e invade outras esferas de ação, provocando a extensão indevida dos critérios da racionalidade instrumental a outras esferas do mundo da vida, anteriormente regidas pela racionalidade comunicativa.

As idéias e preocupações de Habermas encaminharam-se de forma distinta em diferentes fases de seus trabalhos. Conforme aponta Freitag (1990), a abordagem epistemológica que o autor desenvolve em Conhecimento e Interesse (1987a) é, primeiro, substituída por uma leitura político-cultural em trabalhos como Ciencia e Técnica como "Tdeologia" (1968) e, posteriormente, por uma abordagem centrada nas competências comunicativas, como em Teoria de La Ación Comunicativa (1987b, 1987c). Entretanto, a sua visão antropo- 
cêntrica, assim como a divisào básica que ele estabeleceu entre trabalho e interação, embora relativizadas pelos fenômenos de autonomização da técnica, não se alteram. O que ocorre é que tais aspectos de sua teoria passam a apresentar uma elaboração muito mais complexa, na qual a razão crítica ordena e prioriza as demais. Esta dinâmica de articulação de razões contraditórias, através da obtenção de consensos normativos e racionais, antevista por Habermas como um projeto para a moderna sociedade democrática, tem possibilidades de concretização com a ajuda de processos participativos baseados em uma comunicaçào emancipada. É neste caminho que Habermas abre um campo de discussões para os ecologistas sociais, conforme é apontado por Lester (1990) e discutido na conclusão deste trabalho.

\section{Habermas e o Pensamento Verde}

Habermas distancia-se do pensamento verde, embora ambos sejam críticos do totalitarismo, da racionalidade tecnocrática, da cultura de massa e do consumismo. Em uma coletânea de entrevistas publicada com o título de Autonomy and Solidarity (1986, p.210), Habermas declara sua adesão ao Partido Social Democrata e avalia as possibilidades de uma aliança entre este e o Partido Verde. Conclui que tal pacto não seria natural, em função da dificuldade em estabelecer-se uma unidade de posições políticas e de projetos de sociedade entre grupos tão heterogêneos, tais como os verdes antiprodutivistas e os social-democratas representados ora por velhos produtivistas, ora por uma nova classe média.

Habermas (1987c, 1987d, 1990) analisou a emergência dos novos movimentos sociais verdes muito mais como expressões de uma resistência às tendências de colonização do mundo da vida, vinda das camadas populares, do que como movimentos portadores de idéias emancipatórias. Tais movimentos são vistos por ele como defensivos e neo-românticos, uma vez que expressam uma crítica à modernidade centrada em argumentos ecológicos. 


\section{A QUESTÃo ECOLÓGICA}

A leitura que o autor fez dos desequilíbrios ecológicos em seu trabalho A Crise de Legitimação do Capitalismo Tardio (1994, p.57-61) foi, naquele momento, influenciada por Meadows, (1972) através do relatório Os Limites do Crescimento, apresentado ao Clube de Roma e tido, então, como uma obra relevante sobre a questão. Segundo essa análise de Habermas, o crescimento das sociedades capitalistas avançadas colocou a sociedade mundial diante de problemas de equilíbrio ecológico e antropológico. Isso porque o sistema capitalista industrial ampliou seus limites de expansão a tal ponto que a dinâmica deste crescimento passou a se confrontar com a natureza em seu sentido amplo. E, assim, comprometendo tanto a natureza externa constituída pelo ambiente, como a natureza interna do homem, constituída pelo seu equilíbrio antropológico (Habermas, 1994, p.59). Nessas condições, o equilíbrio ecológico e o antropológico definem limites para o crescimento, de forma que tais limites só podem ser ultrapassados às custas do comprometimento das condições de vida no planeta e da alteração da identidade sociocultural dos sistemas sociais. Um problema adicional que se coloca para a avaliação destes desequilíbrios, segundo Habermas (1994), refere-se às dificuldades do estabelecimento dos fundamentos empíricos que permitam estabelecer os limites mencionados.

O dilema ecológico apontado por Habermas (1994) decorre do fato de que as sociedades capitalistas não podem proceder à limitação de seu crescimento sem abandonar os princípios que governam sua organizaçào. A mudança de um modelo de crescimento natural, não planejado, para um modelo de crescimento qualitativo, que privilegiasse o reequilíbrio, tanto ecológico, como antropológico, implicaria numa reorganização dos processos produtivos, os quais precisariam ser replanejados em termos de valores de uso. Essa orientação, contudo, implicaria em uma mudança nos valores centrais que orientam o desenvolvimento das forças produtivas no sistema capitalista, e, consequentemente, na mudança da lógica do próprio sistema.

Temáticas, Campinas, 4(7):9-29, jan./jun. 1996 
Entretanto, segundo Habermas, tal desenvolvimento das forças produtivas nào pode ser desacoplado da produção de valores de troca sem violar a lógica interna do sistema capitalista.

Na conclusào desse trabalho sobre a crise do capitalismo, Habermas (1994) nega a possibilidade de um planejamento centralizado e não participativo como recurso para assegurar a reprodução das condições de existência do sistema social, tanto no que se refere aos aspectos ecológicos, como antropológicos. A reflexào final de Habcrmas, nesse texto, evidencia a importância da razão e da açào racional no encaminhamento da questão. Fala de um agir racional, o qual, ao nivel das soluções ecológicas, implica uma racionalidade instrumental, e, em nivel da questão antropológica, uma racionalidade normativa, emancipatória, que ordena e prioriza a primeira, sendo ambas mediadas por uma relação intersubjetiva com a natureza.

\section{RoByn ECKERSLEY E A ECOLOGIA PROFUNDA}

Robyn Eckersley (1990) faz parte da ala ecocêntrica do movimento verde denominada ecologia profunda, que se destaca por procurar trazer para o espaço das decisões políticas nào apenas as futuras gerações, mas também todas as espécies vivas. De acordo com teóricos ecocêntricos, como Eckersley (1990), é preciso mudar a posição antropocêntrica, centrada no homem, para uma visão ecocêntrica, centrada na terra, sob pena de estar empobrecendo a vida social, o meio ambiente global e de contribuir para a ocorrência de perdas no mundo natural. Para esse grupo, a crise ecológica não é simplesmente uma crise de bem-estar, de sobrevivência e de participaçào humana na democracia. Trata-se de uma crise que afeta todos os membros da comunidade biótica e configura-se como uma crise planetária de proporçòes evolucionárias.

O pleito dos teóricos ecocêntricos é pela liberação do mundo não humano de um status de recurso, riqueza, produto e de caricatura humana. 
De acordo com tal visão, a solução da crise ecológica passa por uma mudança na orientação da ordem mundial, de antropocêntrica para ecocêntrica, na qual se pensa a natureza como “... uma malha de nós na rede biosférica ou no campo das relações intrinsecas...” (Naess apud Eckersley, 1990, p.740), em vez de partes de uma ordem hierárquica na qual o homem ocupa o topo.

Eckersley defende um tipo de abordagem ecocêntrica conhecida como ecologia profunda ou como ecologia transpessoal. Tal orientação tem como preocupação central o desenvolvimento de capacidades ou experiências que se estendam para além do sentido do ego, biográfico ou pessoal e incluam todos os seres. Em outras palavras, de acordo com Eckersley (1990), o interesse da ecologia transpessoal é o cultivo de um sentido maior de si mesmo, através de um processo psicológico de identificação com a natureza e com o cosmos, partindo da visão particular de que todos fazem parte da "ánvore da vida" (Naess apud Eckersley, 1990).

Eckersley, como um teórico ecocêntrico, desenvolve uma análise crítica do trabalho de Habermas. Segundo o referido autor, há dois níveis, em relação aos quais a Tcoria Crítica de Habermas é deficiente: primeiro, no que se refere às relações entre os homens e o mundo não humano, segundo, no que se refere às comunicaçòes inter-humanas pensadas como o modelo de interação para as sociedades democráticas. No que se refere ao primeiro aspecto, Eckersley enfatiza sua discordância em relação ao caráter rígido da categorização habermasiana dos interesses cognitivos e das possibilidades de conhecimento e de controle da natureza, através da ciência e tecnologia. Esse caráter rígido das distinções, segundo o referido autor, serve apenas para legitimar a exploração contínua da natureza, apoiando mais do que desafiando os preconceitos antropocêntricos dominantes frente ao mundo não humano.

No que se refere ao segundo aspecto, para o ecocentrismo é essencial o reconhecimento de que os humanos são parte da natureza e não separados ou superiores a ela. Este reconhecimento baseia-se numa filosofia de acordo com a qual todos os organismos estão relacionados de modo proTemáticas, Campinas, 4(7):9-29, jan./jun. 1996 
fundo com o meio ambiente. De acordo com esta visão, o mundo é uma teia de relações dinâmicas $\mathrm{e}$ inter-relacionadas, na qual não há hierarquia entre as entidades nem uma linha divisória entre as diversas categorias de seres. Num sentido biológico, psicológico e social, segundo o pensamento ecocêntrico somos todos constituídos por nossas interações em meio a outros seres humanos e instituiçòes sociais, econômicas e culturais. Neste modelo interacionista o mundo nào humano não é visto simplesmente como requisito ou meio para a auto-realização humana, mas seus diferentes membros são considerados como tendo sua própria autonomia relativa e sua própria maneira de ser.

Dentro dessa visão, o pensamento de Echersley contrasta com a teoria crítica, negando a concepção habermasiana de progresso, sua visão antropocêntrica, bem como sua análise sobre a questão da racionalidade.

Segundo a taxionomia de Lester (1990), o pensamento de Eckersley (1990) classifica-se como uma autêntica expressão da ecologia profunda, marcado por sua orientação biocêntrica, descentralizadora, não hierarquizada e holística.

\section{CONCLUSÕES}

Diante dessa multiplicidade de visões, a indagação que imediatamente se coloca é a de como pensar essa problemática, qual ângulo de visão selecionar e quais coloridos atribuir a ela.

Considerando a questão do desenvolvimento sustentado em relação às sociedades contemporâneas, acredito serem adequadas as reflexões de Dryzek (1987), um ecologista crítico, segundo Lester (1990), quando discorre sobre a possibilidade de repensar os paradigmas que orientam as discussòes sobre o problema da racionalidade, tomando como referência o pensamento habermasiano.

Habermas, ao pensar um projeto para a modernidade, considera as relações homem-natureza no âmbito da racionalidade instrumental, mas Temáticas, Campinas, 4(7):9-29, jan./jun. 1996 
submete o agir racional com relação a fins ao controle dos meios de comunicação e a vontade coletiva apoiada na prática comunicativa dos indivíduos. Tal possibilidade, das relações homem-natureza pautadas pela racionalidade instrumental serem mediadas por uma racionalidade inter-subjetiva e subsumidas a normas de consenso, é condicionada ao exercicio continuado de relações dialógicas ao nível das comunidades, dentro de uma sociedade democrática participativa. Esta articulação entre as diferentes instâncias da ação racional abre caminho para a superação de processos de "cientificização da técnica" (Habermas, 1968, p.72) e de outras formas de "colonização do mundo da vida" (Habermas, 1987c, p.502), distorções que as crises do capitalismo avançado têm evidenciado.

Segundo John Dryzek (1987), é possível falarmos em uma racionalidade ecológica definida como a capacidade dos ecossistemas proverem, de modo efetivo e consistente, o bem-estar e a manutenção da vida humana. Tal racionalidade, enquanto interesse generalizável, voltado para a manutençào de sistemas naturais, terá, no contexto de uma sociedade participativa, antecedência lógica sobre outros princípios normativos, como a maximização das utilidades ou a proteção aos direitos. Contudo, segundo o autor, estas possibilidades estarão restritas aos seres falantes, não havendo espaço para a natureza não falante vir a ser considerada, uma vez que a reciprocidade igualitária, implícita na comunicação humana, não pode ser estendida para a relação entre os homens e a natureza, porque tal comunicação pressupõe referentes humanos livres e autônomos.

Uma outra leitura interessante sobre a questão, feita por Brüzeke (1994), refere-se à possibilidade de, através da teoria habermasiana, podermos trabalhar com o paradigma do desenvolvimento sustentado. $\mathrm{O}$ autor chama a atenção para a discussão que Habermas (1987) faz do processo de racionalização parcial. Segundo Habermas,

“... um modelo seletivo de racionalização surge quando ao menos um dos três componentes constitutivos da tradição cultural não é objeto de uma elaboração 
sistemática, ou quando ao menos uma das esferas culturais de valor só se institucionaliza de forma insuficiente, isto é, sem que tal institucionalização tenha efeitos estruturais para a sociedade global, ou quando ao menos uma das esferas da vida prevalece até tal ponto sobre as outras, que submete as outras formas de vida a uma racionalidade que lhes é estranha...".(1987b, p.313)

De acordo com a leitura de Brüzeke (1994, p.10), ao focalizar este processo:

“... a crise não está na razão, mas na sociedade moderna. Não na ideia de modernidade, mas na sua realização (...). O capitalismo caminbou para uma racionalização não equilibrada da economia, da administraf̧ão, a custos de outras esferas vitais...."

Tal argumentação tem a vantagem, segundo Brüzeke (1994), de não confrontar aspectos racionais e não racionais, mas de trabalhar com racionalizações parciais, que criam certas ordens, causando processos desequilibrados, que têm caraterísticas de desestruturação e de caos eco-sociológico. Desequilíbrios que são passiveis de resgate, pois o

... desenvolvimento sustentável se propõe nada menos do que resgatar uma racionalização completa, o que inclui o respeito aos próprios limites da razão, buscando um equilibrio entre as diferentes lógicas do social, do econômico e do ecológico... (Brüzeke, 1994, p.12).

Concordo com Brüzeke (1994). Sua leitura da Teoria da Ação Comunicativa de Habermas possibilita um tratamento da questão ambiental segundo uma dinâmica positiva do progresso, salvaguardando a possibilidade de uma adesão racional ao projeto da modernidade e, ao mesmo tempo, assegurando a busca de soluções sustentáveis ambientalmente como alternativas aos processos que caracterizam o capitalismo avançado.

O conceito de desenvolvimento sustentado, apesar das contradições que o envolvem, constitui-se como uma idéia-força, possibilitando a busca de modos tecnológicos alternativos, de cujas possibilidades Habermas parecia duvidar, quando afirmava: 
“... Se, pois, se tem presente que a evolução técnica obedece a uma lógica que corresponde à estrutura da ação teleologica e controlada pelo êxito -- e isto significa: à estrutura do trabalbo -- então, não se vê como poderiamos renunciar à técnica, isto é, à nossa técnica, substituindo-a por uma qualitativamente distinta, enquanto bouvermos que manter a nossa vida por meio do trabalho social e com a ajuda dos meios que substituem o trabalho (...) Seja como for, as realizaçōes da técnica que, como tais, são irrenunciäveis, não poderiam ser substituidas por uma natureza que abre os olbos. A alternativa à técnica existente, o projeto da natureza como interlocutor em vez de objeto, refere-se a uma estrutura alternativa de ação: à interação simbolicamente mediada, que é diferente da ação racional teleológica. Mas isso quer dizer que os dois projetos são projeções do trabalho e da linguagem, projetos, pois, do gênero bumano na sua totalidade e não de uma época singular, de uma classe determinada ou de uma situação ultrapassável. Assim como não é admissivel uma nova técnica, também não pode pensar-se de um modo consequente a idéia de uma nova ciência, já que no nosso contexto ciência deve significar sempre a ciência moderna, uma ciência obrigada a manter a atitude de uma possivel disposição técnica: tal como para a sua função, assim também para o progresso cientificotécnico em geral não existe substituto algum que seria mais bumano... (Habermas, 1968, p.52-53)

Em relação a este ponto, acredito ser importante, inicialmente, estabelecer um distanciamento da posição de Habermas, para analisar a questão com maior grau de liberdade.

Uma indagaçào que se coloca é a de como pensar o desenvolvimento sustentado como a idéia articuladora de um projeto global.

Brüzekc (1994) mostra como o conceito de desenvolvimento sustentado assumiu um porte de universalidade, o que lhe assegura, de acordo com a leitura habermasiana, a dimensão de um projeto alternativo de desenvolvimento para a espécie humana:

"... O conceito de desenvolvimento sustentável tem uma conotação extremanente positiva. Tanto o Banco Mundial, quanto a UNESCO e outras entidades internacionais adotaram este conceito para marcar uma nova filosofia do desenvolvimento que combina eficiência econômica com justiça social e pridência ecológica (...). O conceito de desenvolvimento sustentável sinaliza uma 
alternativa às teorias e aos modelos tradicionais do desenvolvimento..." (Brüzeke, 1994, p.6)

Este conceito, pelas contradições econômicas, políticas e sociais que o envolvem, parece ter possibilidades de concretização apenas através da articulação, em rede, de uma infinidade de projetos particulares de inumeráveis “...sociedades sustentáveis...” (Diegues, 1992) Tais projetos não têm isoladamente um porte universal, mas ganham essa dimensão pela sua articulaçào em redes.

No que se refere a estas redes, podemos identificá-las direcionandose para diferentes projetos de sustentabilidade, desde aqueles desenvolvidos pelas instituições convencionais de pesquisa até os desenvolvidos dentro dos circuitos alternativos. Dentre tais redes mencionamos, por exemplo, uma das listas de discussão sobre controle biológico, a BIOCONTROL-L, bem como a THIRD WORLD NETWORK, voltada para as questões ambientais e com ênfase nos problemas do terceiro mundo, articulando-se através da INTERNET. Outras redes começam a formar-se envolvendo, também, pequenos agricultores ecológicos de caráter mais artesanal e concretizam-se, esporadicamente, através de eventos como os Fóruns Globais, ou de iniciativas de articulação dos mercados comuns, voltadas para assegurar a integridade dos produtos agrícolas, como o "selo verde", "o selo biodinâmico", o "selo orgânico".

No que se refere à discussão sobre os modelos de racionalidade, essa questão parece envolver uma problemática ainda em construção. Concordo com Habermas quando ele evidencia que existem esferas no terreno da eficácia, onde a razão emancipadora parece ser a razão, que resguarda o caráter teleológico da razão instrumental, ao mesmo tempo que a disciplina e a submete aos critérios éticos de uma sociedade democrática e emancipada. Por outro lado, em outras esferas da vida a razão emancipadora é a razão crítica. Numa sociedade democrática e participativa caberá à razão crítica estabelecer o limite e o lugar de cada coisa, enquanto cabe ao exercício per- 
manente da emancipação o papel de alargar esses limites e suplantar suas contradições.

ABSTRACT: In this paper I examine different interpretations of the man-nature relations and of the ecological dilemma, through the analyses of the position of paradigmatic authors, like Paehlke, Eckersley and Habermas, using the classification proposed by Lester. In face of the multiple views about the ecological question, I try to understand them, interpretate them and construct a reading sustained by Habermas, Drysek and Brüzek. It's an alternative that works with the notion of sustainable development, understood as an idea-force that makes possible the search of tecnological ways enrolled in an ecological rationality that links, in a net, a variety of particular projects of "sustainable societies".

KEYwORDS: man-nature relations, ecology, rationality; ideology; sustainable development, nets, sustainable societies.

\section{REFERÊNCIAS BIBLIOGRÁFICAS}

BRANDÃO, C. R. Somos as águas puras. Campinas: Papirus, 1994.

BRÜZEKE, J. F. Desestruturação sócio-econômica e desenvolvimento sustentável. In: Associação Nacional de Pós-Graduação e Pesquisa em Ciências Sociais (ANPOCS), XVIII, 1994, Caxambu (mimeo).

DRYSEK, J. Rational choice: environment and political economy. Oxford: Basis Blackwell, 1987.

CAPRA, F. The turning point: science, society, and rising culture London: Fontana, 1983.

DIEGUES, A. C. Desenvolvimento sustentável ou sociedades sustentáveis. São Paulo em Perspectiva, São Paulo, v. 6, n 1/2, p.22 a 29, jan/junho, 1992.

ECKERSLEY, R. Habermas and green political thought: two roads diverging. Theory and Society, Sidney, n. 19, p.739-776, 1990.

Temáticas, Campinas, 4(7):9-29, jan./jun. 1996 
FERREIRA, L. da C. Estado e Ecologia: Novos Dilemas e Desafios. Tese de Doutorado em Ciências Sociais, IFCH. Campinas: UNICAMP, 1992. FREITAG, et al. Habermas. São Paulo: Editora Ática, 1990. (Coleção Grandes Cientistas Sociais).

HABERMAS, J.. Ciência y técnica como "ideologia". Madrid: Tecnos, 1968. . Autonomy and solidarity (Interviews), London: Verso, 1986.

. Conbecimento e interesse. Rio de Janeiro: Editora Guanabara, 1987a.

. Teoria de la acción comunicativa. Racionalidad de la acción y racionalización social. Madrid: Taurus, 1987b. v.1.

. Teoria de la acción comunicativa. Racionalidad de la acción y racionalización social. Madrid: Taurus, $1987 \mathrm{c}$, v2. . Um Perfil filosófico político. Entrevista com Juergen Habermas. Novos Estudos Cebrap. Sào Paulo, n. 18, Set. 1987d. . Passado como futuro. Rio de Janeiro: Tempo Brasileiro, 1990. - A crise de legitimação no capitalismo tardio. Rio de Janeiro: Tempo Brasileiro, 1994.

HARDIN, G. The tragedy of the commons. Science, v. 162, 1968.

LESTER, J., DRYSEK, J. Alternative views of the environmental problematic. In: Lester, J., org.. Environmental politics and policy: theories and evidence. London: Duke University Press, 1990.

MEADOWS, D. L.. Limits to growth. Nova York, 1972.

ODUM, E. P. Fundamentals of ecology, Filadelfia: Saunders, 1971.

PAEHLKE, R. Environmentalism and the future of progressives Politics. New Haven: Yale University Press, 1989.

VIOLA, E. A. . Dinâmica do ambientalismo e o processo de globalizaçào.

São Paulo em Perspectiva, São Paulo: SEADE, v.6, n.1/ 2, p.6-12 jan/jun.1992. 